\title{
Antiaging Activity of Peptide Identified from Fermented Trapa Japonica Fruit Extract in Human Dermal Fibroblasts
}

\author{
Jin Dong Jang $\mathbb{D}^{1},{ }^{1}$ Minkyung Kim, ${ }^{1}$ Gun-He Nam, ${ }^{2}$ Young-Min Kim, ${ }^{2}$ Sang Moon Kang, \\ Kee-Young Lee, ${ }^{3}$ and Young-Joon Park $\mathbb{D}^{4}$ \\ ${ }^{1}$ Doori Cosmetics Co., Ltd., 13F Galaxy Tower, 175 Saimdang-ro, Seocho-gu, Seoul, Republic of Korea \\ ${ }^{2}$ Department of Biological Science and Biotechnology, College of Life Science and Nano Technology, Hannam University, \\ 1646 Yuseong-daero, Yuseong-gu, Daejeon 34054, Republic of Korea \\ ${ }^{3}$ A\&PEP INC., 13, Oksansandan1-ro, Oksan-myeon, Heungdeok-gu, Cheongju-si, Chungcheongbuk-do, Republic of Korea \\ ${ }^{4}$ College of Pharmacy, Ajou University, 206, World Cup-ro, Yeongtong-gu, Suwon-si, Gyeonggi-do, Republic of Korea
}

Correspondence should be addressed to Young-Joon Park; parkyj64@ajou.ac.kr

Received 14 November 2019; Revised 19 February 2020; Accepted 25 February 2020; Published 30 April 2020

Academic Editor: Juntra Karbwang

Copyright ( 2020 Jin Dong Jang et al. This is an open access article distributed under the Creative Commons Attribution License, which permits unrestricted use, distribution, and reproduction in any medium, provided the original work is properly cited.

\begin{abstract}
We have previously shown that Trapa japonica fruit extract (TJE) as well as its fermented extract (FTJ) can be potentially used to treat alopecia. In the current study, a newly synthesized peptide (PEP) was detected in an active compound isolated from FTJ. Several biological assays were conducted to verify the antiaging effects of TJE, FTJ, and PEP on the skin. We examined the effects of TJE, FTJ, and PEP on cell viability, collagen synthesis, and inhibition of mRNA expression of matrix metalloproteinases (MMPs), induced by tumor necrosis factor alpha (TNF- $\alpha$ ), in human dermal fibroblasts (HDFs). In addition, a wound-healing assay of the human keratinocyte cell line $(\mathrm{HaCaT})$ and a clinical study of antiaging activity were conducted. The findings confirmed that PEP exerted an effect on cell proliferation in a dose-dependent manner. Treatment with TJE, FTJ, and PEP increased collagen synthesis but inhibited TNF- $\alpha$-induced mRNA expression of MMPs. Compared with TJE and FTJ, PEP promoted a significant level of wound recovery in $\mathrm{HaCaT}$ cells and also exhibited antiaging effect, as demonstrated by a clinical study. These results suggest that PEP shows potential as a skin antiaging cosmetic product.
\end{abstract}

\section{Introduction}

Skin aging is a complex biological process involving both intrinsic and extrinsic factors [1]. Intrinsic aging is due to inevitable, natural processes associated with genetics, hormones, and cellular metabolism, resulting in increased fine wrinkles and skin surface roughness as well as thin and dry skin. Extrinsic aging, which is characterized by coarse wrinkles, furrows, roughness, dryness, sagging skin, laxity, loss of elasticity, and pigmentation, is induced by long-term accumulation of external environmental factors such as sun exposure, pollution, smoking, and improper lifestyle [2, 3].

Several studies have reported that skin aging occurs via a variety of molecular mechanisms including oxidative stress, DNA damage and mutations, telomere shortening, inflammation, and the accumulation of advanced glycation end products (AGEs) [4-6]. Furthermore, reactive oxygen species (ROS) cause skin aging by stimulating the expression of matrix metalloproteinases (MMPs) that contribute to skin aging by degrading various components of extracellular matrix (ECM) proteins such as collagen, fibronectin, elastin, and proteoglycans $[7,8]$.

Interest in antiaging products is rapidly increasing due to a significant growth in the aging population. As a result, focus on antiaging skin products has increased, with particular reference to the thriving cosmetics market [9]. Thus, studies leading to the development of functional antiaging cosmetic products using natural ingredients, that are neither toxicants nor skin irritants, are actively being pursued [10].

Peptides are considered as useful cosmetics material, because they are light and air stable, less toxic, exhibit a strong affinity for water, and possess moisturizing capacity 
$[11,12]$. They are widely used as ingredients in functional cosmetic products with antioxidant, anti-inflammation, collagen synthesis, antiwrinkle, whitening, and woundhealing effects which are intended to improve skin conditions [13-15]. Recently, the development of novel natural peptides, as well as more stable and effective synthetic peptides, has raised interest in the use of peptide-based cosmetics in skin care $[16,17]$.

Trapa japonica, a well-known aquatic plant, belongs to the genus Trapaceae. It is rooted in the water, while its thin, long stems containing aerocysts float on water. It is mostly found in shallow water fields, reservoirs, or ponds around the country [18]. It contains high starch levels, many dietary fibers, and polyphenols, such as trapain, ellagic acid, eugeniin, and gallic acid $[19,20]$. Previous studies have shown that $T$. japonica exhibits antidiabetic activity in addition to exerting antioxidant and anti-inflammatory effects. It also exerts inhibitory effects on ultraviolet B- (UVB-) induced expression of $11 \beta$-hydroxysteroid dehydrogenase type $1(11 \beta-H S D 1)$ [21-24]. Previously, our studies indicated that the active ingredients of the T. japonica fruit extract were supplemented by fermentation with two microorganisms: Bacillus subtilis and Bacillus methylotrophicus $[25,26]$. We additionally demonstrated that the fermented T. japonica fruit extract induced the proliferation of human hair follicle dermal papilla cells.

In this study, we examined compounds isolated from the fermented T. japonica fruit extract and synthesized a new peptide, which was identified structurally. Furthermore, we investigated the antiaging effect of the newly synthesized peptide via in vitro tests and a clinical study.

\section{Materials and Methods}

2.1. Materials and Reagents. Trifluoroacetic acid (TFA) was purchased from Sigma-Aldrich Co., (St. Louis, MO, USA. Ethanol, methanol, hexane, chloroform, ethyl acetate, n-butane, and HPLC-grade water were purchased from Duksan Chemicals Co. (Seoul, Korea)). All samples were filtered using the PTFE membranes $(0.2 \mu \mathrm{m}$; Adconcinc MFS Inc.) before injection. Human keratinocyte-derived $\mathrm{HaCaT}$ cells and human dermal fibroblasts (HDFs) were obtained from the American Type Culture Collection (ATCC, Manassas, VA, USA).

2.2. Plant Material and Fermentation. T. japonica fruits (Voucher number: KP255650) were obtained from China. Next, $500 \mathrm{~g}$ of dried T. japonica fruit was extracted with $5000 \mathrm{~mL}$ of distilled water for $24 \mathrm{~h}$ at $50^{\circ} \mathrm{C}$ and filtered using a filter funnel and filter paper. $3.67 \%(\mathrm{w} / \mathrm{w})$ of $T$. japonica fruit was obtained as an extract (TJE). Fermentation of TJE was performed using B. subtilis (K007) and B. methylotrophicus (S001), which were separately identified by A\&PEP Inc (Cheongju, Korea). After preculturing in nutrient broth (Difco, Detroit, MI, USA) for $24 \mathrm{~h}$ with shaking in an incubator at $37^{\circ} \mathrm{C}$, the two microorganisms were inoculated into the medium $(0.6 \%$ glucose, $0.3 \%$ yeast extract, and $0.1 \%$ soytone) containing
TJE in a fermenter ( FMT ST-D-14; Fermentec, Korea) at $37^{\circ} \mathrm{C}$ for $3 \mathrm{~d}$. The final fermentation product was filtered using a $0.2 \mu \mathrm{m}$ filter.

2.3. Fraction and Isolation. The fermented T. japonica fruit extract (FTJ) was sequentially fractionated with hexane, chloroform, ethyl acetate, butanol, and water. The water fraction was concentrated using a rotary vacuum concentrator (RE100-pro; DLAB Scientific Inc., USA). Six fractions were separated using a Sephadex-LH20 column and a RP silica column in sequence and were purified via high-performance liquid chromatography (HPLC). HPLC was performed using a Waters 2690 Separation Module and a Waters 2487 Dual $\lambda$ Absorbance Detector. The analytical column (Xterra C18 ODS, $0.5 \times 250 \mathrm{~nm}$ ) was packed with LiChrospher 100RP-18 (15 $\mu \mathrm{m}$; Merck Co.). The final compound obtained via a further HPLC process was confirmed to be a tripeptide by nuclear magnetic resonance (NMR; 1H, 13C, 2D-NMR).

2.4. Peptide Synthesis. The peptide (PEP) was synthesized using 3 amino acids. Swelling was induced via the addition of 2-chlorotrityl chloride resin and methylene chloride (MC), following which an amino acid and diisopropylethylamine (DIPEA) were also added, together with dimethyl formamide (DMF). Next, a deblocking solution was added and the preparation was washed using MC. A second amino acid was allowed to react with the mixture of $\mathrm{N}$-hydroxybenzotriazole (HOBt) and $O$-(benzotriazol-1-yl)- $N, N, N^{\prime}, N^{\prime}$-tetramethyluranium hexafluorophosphate (HBTU) dissolved in DMF and DIPEA. Next, deblocking solution was added and the preparation was washed using MC. A third amino acid was also allowed to react via the same method. The reaction mixture was concentrated and purified using HPLC.

2.5. WST-1 Assay. Cell proliferation was determined using water-soluble tetrazolium salt (WST-1; EZ-CytoX, Daeil Lab Service, Korea). HDFs were cultured in Dulbecco's Modified Eagle's Medium (DMEM; Welgene, Korea) containing 10\% fetal bovine serum (FBS) for $24 \mathrm{~h}$ in a humidified incubator under $5 \% \mathrm{CO}_{2}$ at $37^{\circ} \mathrm{C}$. Cells were treated with a range of test sample concentrations $(0-1 \mu \mathrm{g} / \mathrm{mL})$ and incubated for $24 \mathrm{~h}$. Absorbance was measured using an ELISA microplate reader (Bio-Rad model 680; Bio-Rad Laboratories Inc., Japan) at $450 \mathrm{~nm}$.

2.6. Measurement of Collagen Synthesis. HDFs were cultured in DMEM supplemented with $10 \%$ FBS for $24 \mathrm{~h}$ in a humidified incubator under $5 \% \mathrm{CO}_{2}$ at $37^{\circ} \mathrm{C}$. The medium was replaced with a serum-free medium and treated with $1 \mu \mathrm{g} /$ $\mathrm{mL}$ of TJE, FTJ, and PEP for $24 \mathrm{~h}$. Collagen synthesis in cell supernatants was quantified using a collagen type 1 c-peptide ELISA kit (Takara Bio Inc.) in accordance with the manufacturer's protocol. 
2.7. Measurement of Reverse Transcription-PCR. mRNA expression levels of MMP-1 and MMP-9 were determined via reverse transcription-polymerase chain reaction (RT-PCR). Following pretreatment with $1 \mu \mathrm{g} / \mathrm{mL}$ of TJE, FTJ, and PEP for $1 \mathrm{~h}$, HDFs were treated with $10 \mathrm{ng} / \mathrm{mL}$ of TNF- $\alpha$ for $24 \mathrm{~h}$. Isolation of total RNA from HDFs was performed using RiboEx ${ }^{\mathrm{TM}}$ solution (GeneAll Biotechnology, Korea). One microgram of RNA was reverse transcribed to complementary DNA (cDNA) using a DiaStar ${ }^{\mathrm{TM}}$ RT kit (SolGent, Seoul, Korea). RTPCR was performed via Rotorgene 3000 real-time PCR (Corbett Research, UK) using PowerUp SYBR ${ }^{\mathrm{TM}}$ Green Master Mix (Takara, Korea) and primers in accordance with the manufacturer's instructions. Glyceraldehyde-3phosphate dehydrogenase $(G A P D H)$ was used as the internal control for data normalization. The following primers were used: $M M P-1,5^{\prime}$-TTTTAATGGGCAGGAGATGC- $3^{\prime}$ and $5^{\prime}$-GGATGATGAAAAGGCTGGAA$3^{\prime}$; MMP-9, 5'-GAGACCGGTGAGCTGGATAG-3' and 5'-TACACGCGAGTGAAGGTGAG-3'; GAPDH, $5^{\prime}-$ TTCCTCGGTGATACCCACTC- $3^{\prime}$ and $5^{\prime}$-AGGACCTTCCCGTTTCACTT-3'.

2.8. Wound-Healing Assay. HaCaT cells were grown in DMEM supplemented with $10 \% \mathrm{FBS}$ at $37^{\circ} \mathrm{C}$ in an incubator under $5 \%$ humidified $\mathrm{CO}_{2}$ for $24 \mathrm{~h}$. The monolayer of cells was scratched with a $10 \mu \mathrm{L}$ sterile pipette tip, following which the cells were washed with phosphate buffered saline (PBS) to remove detached cells. Next, cells were treated with the test samples $(1 \mu \mathrm{g} / \mathrm{mL})$ for $24 \mathrm{~h}$. The area of wound repair was assessed under a light microscope (Carl Zeiss, Thornwood, NY, USA) equipped with a digital camera.

2.9. Clinical Trial to Determine the Antiaging Effect. The clinical study was approved by the local ethics committee (KDRI-IRB-18659, Korea) and performed in compliance with the Declaration of Helsinki and Good Clinical Practice guidelines (GCP). All procedures were performed in accordance with ethical standards. Informed consent was obtained from all participants ( 22 healthy women, aged 41 to 57 years). The subjects applied the test sample (eye cream containing $0.5 \%$ PEP) to their face twice a day for 8 weeks. The components of the eye cream are shown in Table 1 . The experimental design comprised a randomized, double blind test. All subjects washed their faces using a standard cleanser and rested under optimal conditions (temperature $20-24^{\circ} \mathrm{C}$, relative humidity $40-60 \%$ ) for $30 \mathrm{~min}$ before being subjected to skin analyses. The skin condition of subjects was evaluated by dermatologists. The antiaging effect of the test sample was evaluated using 5 parameters (R1, skin roughness; R2, maximum roughness; R3, average roughness; R4, smoothness depth; R5, arithmetic average roughness) via a Skin-Visiometer SV600 (CK electronic $\mathrm{GmbH}$, Germany). Clinical data were statistically analyzed using Minitab 18 (Minitab $18.1^{\circledR}$; Minitab Inc.) program.

2.10. Statistical Analysis. All data were expressed as mean \pm standard deviation of three independent
TABLE 1: The components of the eye cream.

\begin{tabular}{lc}
\hline Component & Amount $(\% \mathrm{w} / \mathrm{w})$ \\
\hline EDTA-2Na & 0.03 \\
Glycerin & 5.00 \\
1,3-Butylene glycol & 5.00 \\
Sorbitol & 5.00 \\
Carbomer & 0.30 \\
Xanthan gum & 0.30 \\
Bees wax & 1.50 \\
Glyceryl stearate & 0.50 \\
Cetearyl alcohol & 4.00 \\
Phytosqualene & 4.00 \\
Carpylic/capric triglyceride & 4.00 \\
Shea butter & 4.00 \\
Dimethicone & 2.50 \\
Fragnance & 0.40 \\
1,2-Hexandiol & 1.50 \\
Tripeptide (5,000 ppm sol.) & 0.5 \\
Water q.s. & 100 \\
\hline
\end{tabular}

experimental replicates. Statistical significance was determined by Student's $t$-test. Statistical significance was set at either $p<0.05$ or $p<0.01$ symbolized by $*$ and $* *$, respectively.

\section{Results and Discussion}

\subsection{Result}

3.1.1. New Peptide Synthesis Identified from FTJ. As previously stated, fermentation of TJE using B. subtilis (K007) and B. methylotrophicus (S001) yielded FTJ. In our recent study, we isolated a tripeptide from FTJ [26]. In brief, the fermented biomass of $T$. japonica was extracted by using water as a solvent, and the extract was fractionated using silica gel and Sephadex LH-20 columns. The fraction with the highest protein content was selected, and further separation of the fraction was conducted through the RP silica column. Using HPLC analysis, the peptide AC2, which was a pure single peptide, was finally isolated [26]. An in vitro efficacy test indicated that this tripeptide exhibited skin-related bioactivities. A novel peptide (PEP) was synthesized from this tripeptide and subsequently identified (Figure 1). This novel PEP was synthesized using three amino acids, and its purity was confirmed by HPLC analysis to be $96.87 \%$.

3.1.2. Effects of TJE, FTJ, and PEP on Cell Proliferation and Collagen Production. We evaluated the effects of TJE, FTJ, and PEP on human dermal fibroblast (HDF) proliferation. The cells were treated with various concentrations (0-1 $\mathrm{g}$ / $\mathrm{mL}$ ) of these 3 substances, following which cell viability was determined via the WST-1 assay. No cytotoxicity was observed up to $1 \mu \mathrm{g} / \mathrm{mL}$ of either TJE, FTJ, or PEP (Figure 2). Furthermore, only PEP showed significant cell proliferation activity in a dose-dependent manner. In order to investigate the effects of TJE, FTJ, and PEP on collagen synthesis, HDFs were pretreated with $1 \mu \mathrm{g} / \mathrm{mL}$ of TJE, FTJ, and PEP for $24 \mathrm{~h}$ and the supernatant was analyzed using a collagen type 1 c-peptide (PIP) ELISA kit. The results indicated that TJE and 


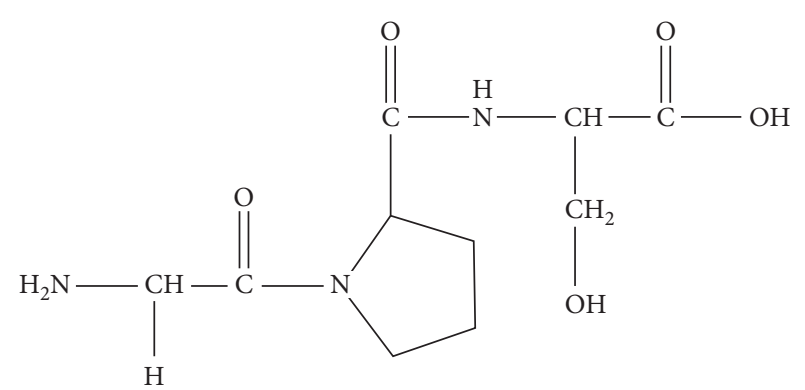

Figure 1: The structure of a peptide derived from fermented Trapa japonica fruit extracts.

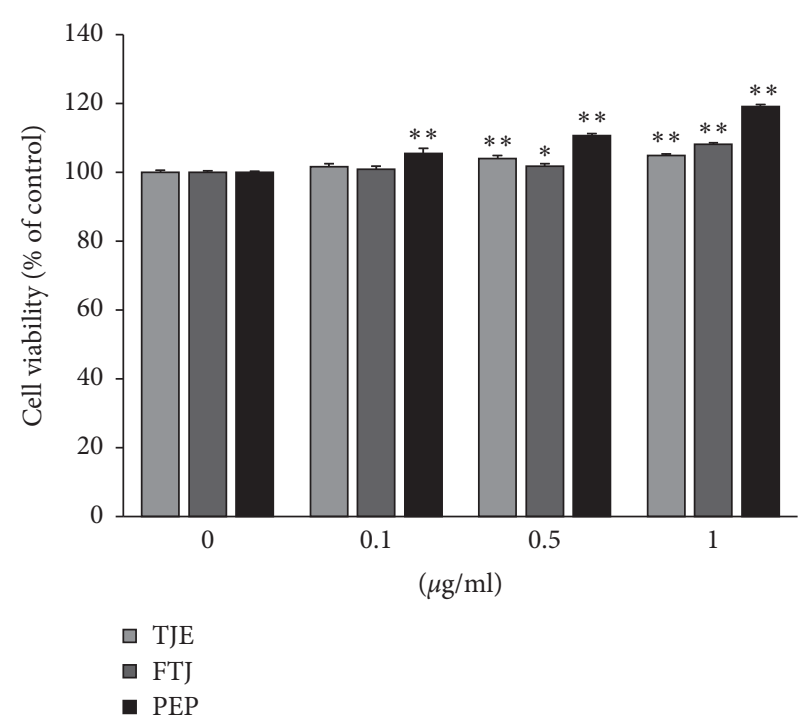

FIgUre 2: Effects of TJE, FTJ, and PEP on cell viability in HDFs. Cells were treated with various doses of TJE, FTJ, and PEP $(0,0.1$, and $0.5,1 \mu \mathrm{g} / \mathrm{mL}$ ) for $24 \mathrm{~h}$. The proliferative effects of TJE, FTJ and PEP were evaluated via a WST-1 assay. Data are presented as mean \pm standard deviation of three independent experiments. ${ }^{*} p$ value $<0.05 ;{ }^{* *} p$ value $<0.01$ vs. untreated group.

FTJ increased collagen production by $33 \%$ and $63 \%$, respectively, compared to the control group (Figure 3). PEP increased collagen synthesis by $95 \%$ which was a significantly higher increase compared to that observed in the control group. Therefore, these results demonstrated that TJE, FTJ, or PEP may protect against skin aging by enhancing collagen production.

3.1.3. Inhibitory Effects of TJE, FTJ, and PEP on MMP-1 and $M M P-9$ Expression Induced by TNF- $\alpha$. The inhibitory effects of TJE, FTJ, and PEP on the mRNA expression of MMPs, induced by TNF- $\alpha$ in HDFs are shown (Figure 4). Cells were pretreated with $1 \mu \mathrm{g} / \mathrm{mL}$ of TJE, FTJ, and PEP and then treated $20 \mathrm{ng} / \mathrm{mL}$ TNF- $\alpha$ for $24 \mathrm{~h}$. The mRNA expression of $M M P-1$ and MMP-9 was determined via RT-PCR. The findings confirmed that TNF- $\alpha$ induced a significant increase in the expression of MMP-1 and MMP-9 mRNA compared with that of the control group (untreated). TJE and FTJ decreased the mRNA expression levels of TNF-

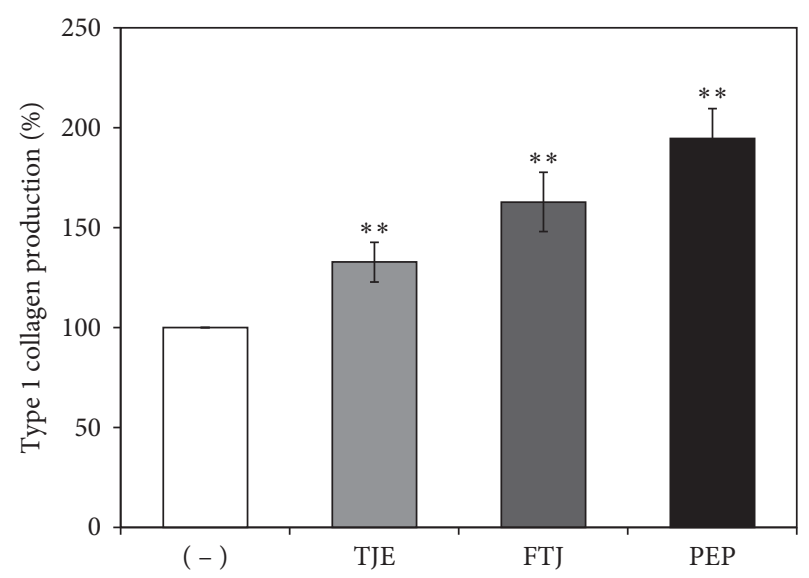

FIgURE 3: Effects of TJE, FTJ and PEP on collagen production in HDFs. Cells were cultured with TJE, FTJ, and PEP at a concentration of $1 \mu \mathrm{g} / \mathrm{mL}$ for $24 \mathrm{~h}$. The supernatant was collected from each well and procollagen type 1 c-peptide (PIP) was measured using an ELISA kit. Data are presented as mean \pm standard deviation of three independent experiments ${ }^{*} p$ value $<0.05$; ${ }^{* *} p$ value $<0.01$ vs. control group.

$\alpha$-induced MMP-1 and MMP-9. However, PEP induced a particularly significant reduction in the mRNA expression levels of MMP-1 and MMP-9 increased by TNF- $\alpha$.

3.1.4. Effects of TJE, FTJ, and PEP on Wound Recovery. Wound recovery activities of TJE, FTJ, FTE and PEP were evaluated in a human-derived keratinocyte cell line (HaCaT) via a scratch wound-healing assay. HaCaT cells scratched by using the pipette tip were treated with $1 \mu \mathrm{g} / \mathrm{mL}$ of TJE, FTJ, and PEP for $24 \mathrm{~h}$. Both FTJ and PEP exhibited wound-recovery activities, whereas TJE did not (Figure 5). Recovery of the scratched area in PEP-treated cells, in particular, was enhanced by 4.4 -fold, which was significant compared to that in the control group.

3.1.5. Antiaging Effect of PEP Observed in Clinical Study. Antiaging activity of PEP was evaluated at the clinical trial level using an eye cream containing $0.5 \%$ PEP. Twenty-two older female volunteers with skin wrinkles were selected from the group. A randomized double-blind test was performed, wherein a test, the sample was applied to the facial area twice a day for 8 weeks. Antiaging effect of PEP was evaluated using a skin visiometer which measured wrinkle parameters as follows: R1, skin roughness; R2, maximum roughness; $\mathrm{R} 3$, average roughness; R4, smoothness depth; and R5, arithmetic average roughness. Results demonstrated that all wrinkle parameters associated with the facial area were significantly decreased when the eye cream containing $0.5 \%$ PEP was used for 8 weeks (Figure 6(a)). Additionally, image analysis confirmed that skin wrinkles were reduced by application of the test sample for 8 weeks (Figure 6(b)). Thus, the current study indicated that PEP exerted an inhibitory effect on skin wrinkling. 

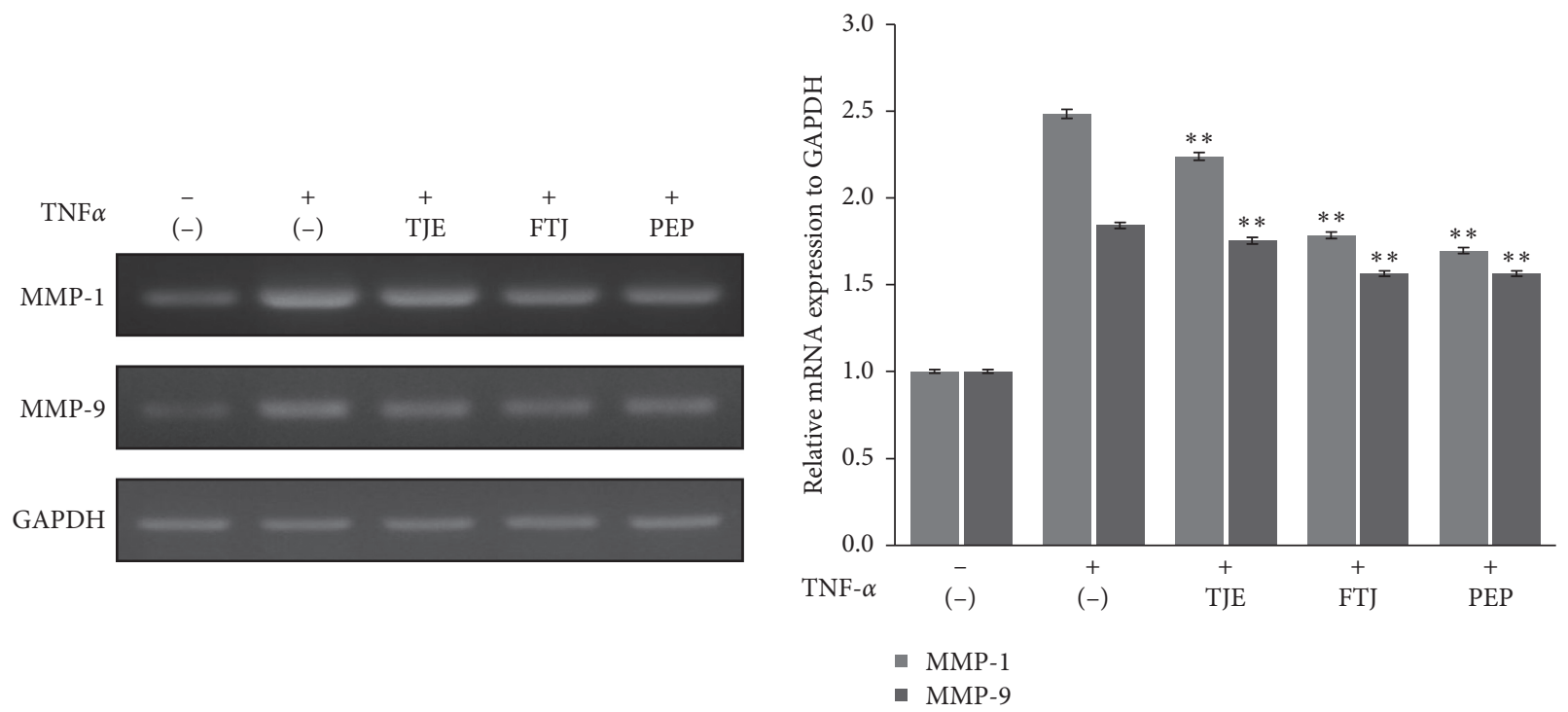

FIgURE 4: Effects of TJE, FTJ, and PEP on TNF- $\alpha$-induced MMP-1 and MMP-9 mRNA levels in HDFs. Cells were pretreated with TJE, FTJ, and PEP at a concentration of $1 \mu \mathrm{g} / \mathrm{mL}$ for $1 \mathrm{~h}$ and then stimulated with $20 \mathrm{ng} / \mathrm{mL}$ TNF- $\alpha$ for $24 \mathrm{~h}$. The mRNA expression levels of MMP-1 and MMP-9 were measured using RT-PCR. GAPDH was used as the internal control. * $p$ value $<0.05 ;{ }^{* *} p$ value $<0.01$ vs. TNF- $\alpha$-treated group.

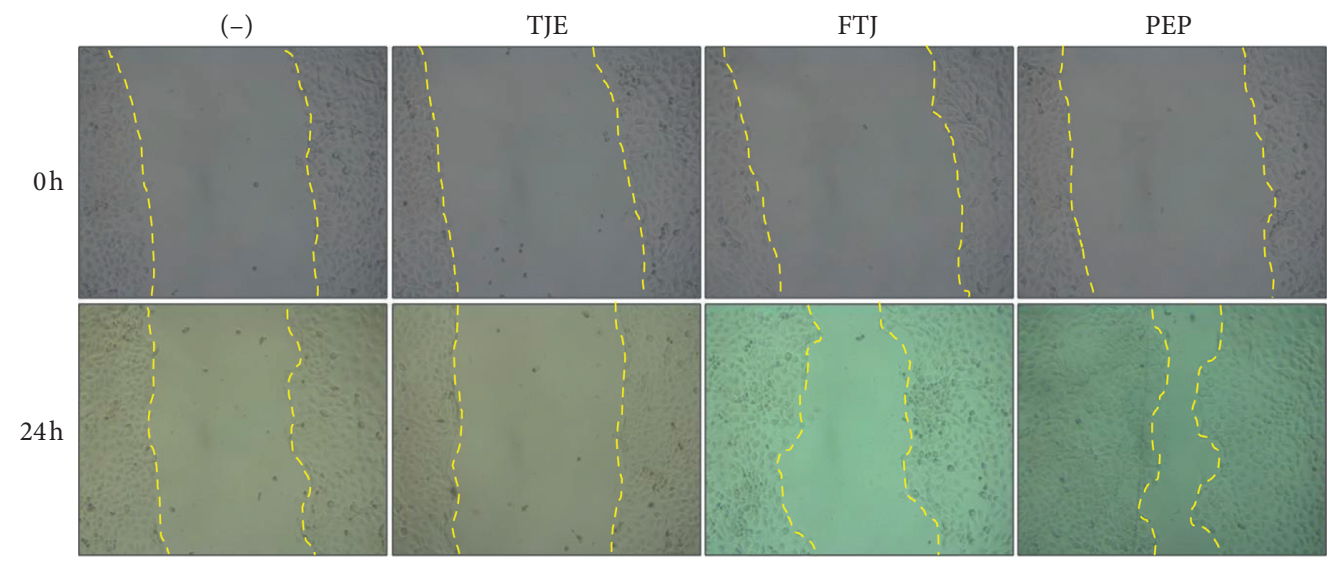

(a)

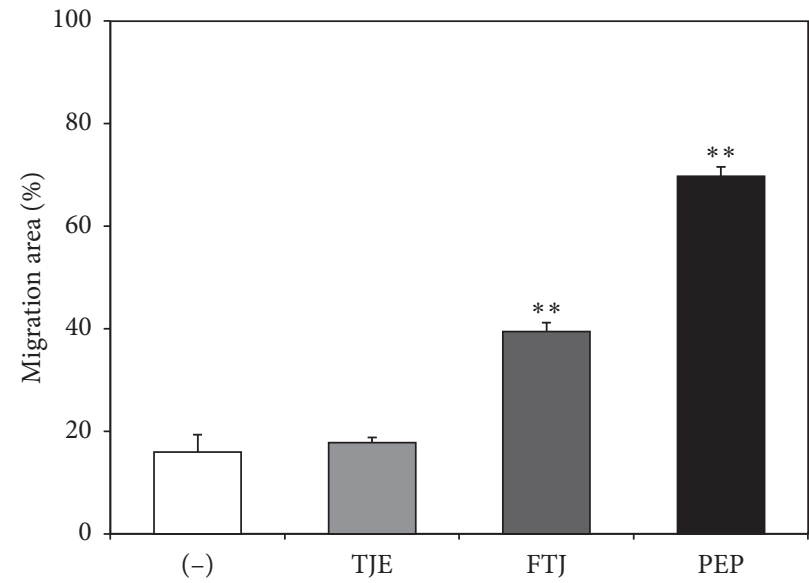

(b)

FIGURE 5: In vitro wound-healing assay of HaCaT. A wound-healing assay was performed to observe the effects of TJE, FTJ, and PEP treatment on $\mathrm{HaCaT}$ wound recovery. Cell monolayers were scratched and treated with TJE, FTJ, and PEP $(1 \mu \mathrm{g} / \mathrm{mL})$ for $24 \mathrm{~h}$. Cell migration into the wound was examined via light microscopy. (a) Yellow dotted lines represent the wound boundary. Quantitative analysis of the migration area was obtained via a wound-healing assay of HaCaT. (b) Data are presented as mean \pm standard deviation of three independent experiments. ${ }^{*} p$ value $<0.05 ;{ }^{* *} p$ value $<0.01$ vs. control group. 


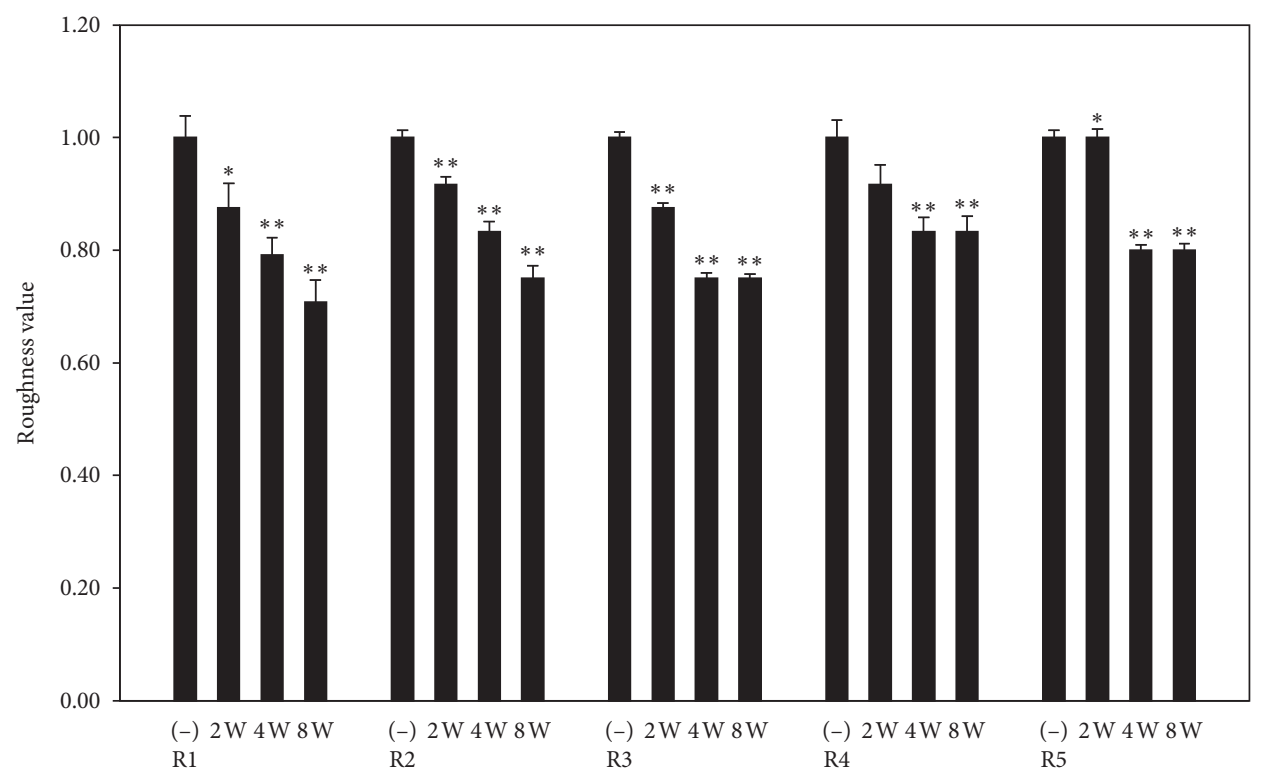

(a)

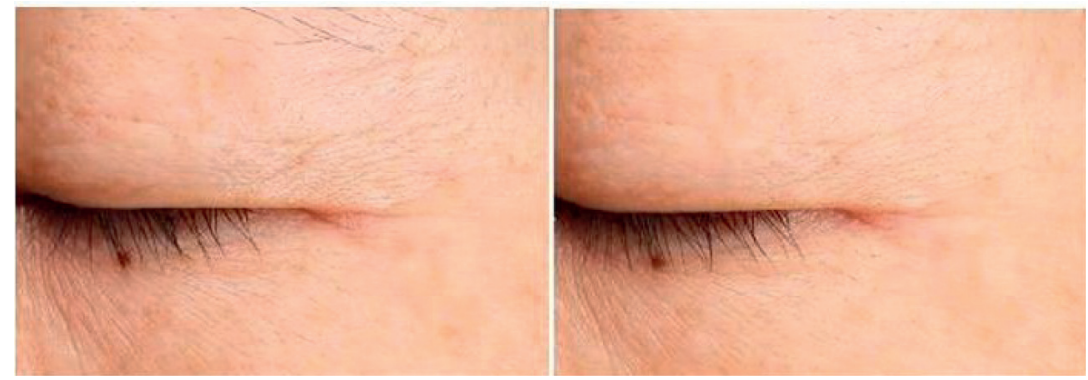

$(-)$

$(8 \mathrm{w})$

(b)

FIgure 6: Clinical study on the antiaging effect of PEP. A formulation containing $0.5 \%$ PEP was applied to the face of 22 female subjects twice a day for 8 weeks. (a) Roughness parameters (R1, skin roughness; R2, maximum roughness; R3, average roughness; R4, smoothness depth; R5, arithmetic average roughness) and (b) representative photographs. ${ }^{*} p$ value $<0.05$; ${ }^{* *} p$ value $<0.01$ vs. control group.

3.2. Discussion. The current study investigated the effect of PEP on antiaging via in vitro clinical studies. In a previous study, we established a water-fermentation process using two microorganisms, B. methylotrophicus and B. subtilis, and conducted solvent fractionation using hexane, chloroform, ethyl acetate, butanol, and water to separate biologically active materials from FTJ [25]. Among the bioactive substances obtained from FTJ, peptides were selectively explored because peptides are extremely effective as ingredients of cosmetic skin-care products due to biological effects such as pigmentation, anti-inflammation, cell proliferation, wound healing, angiogenesis, and antiaging [13]. In addition, peptides are attracting attention as cosmeceutical materials that are suitable for use in antiaging skin care because of the ability to synthesize extracellular matrix (ECM) tissue that play an important role in skin aging [15]. Evaluation of protein content after separation and purification confirmed that FTJ contains a significantly higher amount of protein than TJE and that the FTJ fraction contained more protein in the water layer than FTJ. Moreover, a pure compound was identified by preparative
HPLC, and its structure and sequences were determined via NMR (1H, 13C, 2D-NMR). In the current study, we developed a new synthesis system which enabled the mass production of highly pure and stable bioactive materials. The new system was then used to synthesize a novel tripeptide (PEP) which displayed structural and sequential similarities to those of the peptides found in FTJ (Figure 1).

In this study, we investigated the effect of PEP on skin antiaging in human dermal fibroblasts (HDFs). Collagen primarily consists of extracellular matrix (ECM) proteins, which are responsible for the integrity, elasticity, and strength of human skin [26]. Degradation and reduction of collagen is closely linked to skin aging. Matrix metalloproteinases (MMPs), which are zinc-containing proteinases, play an important role in the process of skin aging via the degradation and modification of ECM proteins, which, in turn, are closely associated with inflammation, carcinogenesis, angiogenesis, and wound healing [27]. Among MMPs, MMP-1, a collagenase, degrades fibrillar collagen type I and III, while MMP-9, a gelatinase, breaks down ECM components such as collagen type I and IV in the skin. 
Reportedly, TNF- $\alpha$, a major inflammatory cytokine, induces MMP-1 and MMP-9 expression and suppresses collagen synthesis in HDFs [28]. We confirmed that PEP was associated with cell proliferation and significant collagen synthesis, which also suppressed TNF- $\alpha$-induced expression of MMP-1 and MMP-9 mRNA in HDFs (Figures 2-4).

We performed a cell migration assay to determine the effect of PEP on wound-healing activity in human keratinocytes. Migration and proliferation of keratinocytes at reepithelialized wound sites are essential factors for tissue healing [29, 30]. We found that scratched HaCaT cells exhibited significant activity during wound healing when treated with $1 \mu \mathrm{g} / \mathrm{mL}$ of PEP (Figure 5).

We performed a clinical study using an eye cream containing $0.5 \% \mathrm{PEP}$ as a cosmetic ingredient. It was confirmed that application of PEP for 8 weeks improved wrinkle parameters involved in skin aging (Figure 6). A clinical trial was conducted using participants over the age of 40, who were concerned about wrinkles, sagging, laxity, and roughness of skin. The result suggested that PEP showed potential as a functional cosmetic product with antiaging effect. However, further studies may be needed to increase the sample size by increasing the number of volunteers to evaluate factors that play an important role in skin aging.

\section{Conclusion}

We synthesized a PEP with the same structure as that of the tripeptide derived from the fermented $T$. japonica fruit extract. We confirmed that the newly synthesized PEP exerted an effect on cell proliferation and collagen synthesis by decreasing the mRNA expression of TNF- $\alpha$-induced MMP-1 and MMP-9 in HDFs. In addition, PEP promoted significant wound recovery in $\mathrm{HaCaT}$ cells and was found to enhance antiwrinkle effect clinically. These findings suggested that PEP showed potential as an antiskin-aging product which may be used in the cosmetic industry. However, this novel PEP may need further investigation, including clinical trials, in order to elucidate detailed molecular mechanisms underlying its effects and to enhance its efficacy as a skin product.

\section{Abbreviations}

TJE: Trapa japonica fruit extract.

\section{Data Availability}

No data were used to support this study.

\section{Conflicts of Interest}

The authors declare that there are no conflicts of interest regarding the publication of this paper.

\section{Acknowledgments}

This work was supported by the Industrial Core Technology Development Program (Grant no. 10077583).

\section{References}

[1] M. A. Farage, K. W. Miller, P. Elsner, and H. I. Maibach, "Intrinsic and extrinsic factors in skin ageing: a review," International Journal of Cosmetic Science, vol. 30, no. 2, pp. 87-95, 2008.

[2] C. Trojahn, G. Dobos, A. Lichterfeld, U. Blume-Peytavi, and J. Kottner, "Characterizing facial skin ageing in humans: disentangling extrinsic from intrinsic biological phenomena," Biomed Research International, vol. 2015, Article ID 318586, 9 pages, 2015.

[3] A. K. Langton, M. J. Sherratt, C. E. M. Griffiths, and R. E. B. Watson, "Review Article a new wrinkle on old skin: the role of elastic fibres in skin ageing," International Journal of Cosmetic Science, vol. 32, no. 5, pp. 330-339, 2010.

[4] M. Rinnerthaler, J. Bischof, M. Streubel, A. Trost, and K. Richter, "Oxidative stress in aging human skin," Biomolecules, vol. 5, no. 2, pp. 545-589, 2015.

[5] Y. Yonei, M. Ichihashi, and W. Takabe, "Age-related diseases of the skin and anti-aging medicine," Nihon Rinsho. Japanese Journal of Clinical Medicine, vol. 74, no. 9, pp. 1541-1547, 2016, (in Japanese).

[6] M. G. Kosmadaki and B. A. Gilchrest, "The role of telomeres in skin aging/photoaging," Micron, vol. 35, no. 3, pp. 155-159, 2004.

[7] M. Luchtefeld, K. Grote, C. Grothusen et al., "Angiotensin II induces MMP-2 in a p47phox-dependent manner," Biochemical and Biophysical Research Communications, vol. 328, no. 1, pp. 183-188, 2005.

[8] R. P. Verma and C. Hansch, "Matrix metalloproteinases (MMPs): chemical-biological functions and (Q)SARs," Bioorganic \& Medicinal Chemistry, vol. 15, no. 6, pp. 2223-2268, 2007.

[9] M. A. Farage, K. W. Miller, P. Elsner, and H. I. Maibach, "Structural characteristics of the aging skin: a review," $\mathrm{Cu}$ taneous and Ocular Toxicology, vol. 26, no. 4, pp. 343-357, 2007.

[10] I. A. Khan and E. A. Abourashed, Leung's Encyclopedia of Common Natural Ingredients: Used in Food, Drugs and Cosmetics, John Wiley \& Sons, Hoboken, NJ, USA, 3rd edition, 2010.

[11] L. Pickart, "The human tri-peptide GHK and tissue remodeling," Journal of Biomaterials Science, Polymer Edition, vol. 19, no. 8, pp. 969-988, 2008.

[12] H.-I. Choi, J.-I. Park, H.-J. Kim, D.-W. Kim, and S.-S. Kim, “A novel L-ascorbic acid and peptide conjugate with increased stability and collagen biosynthesis," BMB Reports, vol. 42, no. 11, pp. 743-746, 2009.

[13] R. Cheung, T. Ng, and J. Wong, "Marine peptides: bioactivities and applications," Marine Drugs, vol. 13, no. 7, pp. 4006-4043, 2015.

[14] R. Sable, P. Parajuli, and S. Jois, "Peptides, peptidomimetics, and polypeptides from marine sources: a wealth of natural sources for pharmaceutical applications," Marine Drugs, vol. 15, no. 4, p. 124, 2017.

[15] C. Aldag, D. Nogueira Teixeira, and P. S. Leventhal, "Skin rejuvenation using cosmetic products containing growth factors, cytokines, and matrikines: a review of the literature," Clinical, Cosmetic and Investigational Dermatology, vol. 9, pp. 411-419, 2016.

[16] J. Tkaczewska, M. Bukowski, and P. Mak, "Identification of antioxidant peptides in enzymatic hydrolysates of carp (Cyprinus carpio) skin gelatin," Molecules, vol. 24, no. 1, p. 97, 2018. 
[17] D. Nath, P. Banerjee, A. Ray, and B. Bairagi, "Green peptidenanomaterials a friendly healing touch for skin wound regeneration," Advanced Nano Research, vol. 2, no. 1, pp. 14-31, 2019.

[18] M. Yasuda, K. Yasutake, M. Hino et al., "Inhibitory effects of polyphenols from water chestnut (Trapa japonica) husk on glycolytic enzymes and postprandial blood glucose elevation in mice," Food Chemistry, vol. 165, pp. 42-49, 2014.

[19] C.-C. R. Wang, J.-Y. Ciou, and P.-Y. Chiang, "Effect of micronization on functional properties of the water caltrop (Trapa taiwanensis Nakai) pericarp," Food Chemistry, vol. 113, no. 4, pp. 970-974, 2009.

[20] K. Shindo, E. Kuroki, and M. Toyoda, "Antioxidative compounds contained in the seed with hard shell of Trapa japonica Flerov. and its herbal tea," Journal of Home Economics of Japan, vol. 64, pp. 353-359, 2013.

[21] M.-J. Kang, S. K. Lee, J.-H. Song et al., "Water chestnut (Trapa japonica Flerov.) exerts inhibitory effect on postprandial glycemic response in rats and free radical scavenging activity in vitro," Food Science and Biotechnology, vol. 18, no. 3, pp. 808-812, 2009.

[22] Y.-S. Kim, J.-W. Hwang, Y.-K. Han et al., "Antioxidant activity and protective effects of Trapa japonica pericarp extracts against tert-butylhydroperoxide-induced oxidative damage in Chang cells," Food and Chemical Toxicology, vol. 64, pp. 49-56, 2014.

[23] J.-J. Nam, K.-E. Lee, J.-E. Park, S.-J. Moon, and J.-K. Youm, "Inhibitory effect of fractionated Trapa japonica extracts on UVB-induced skin photoaging," Journal of the Society of Cosmetic Scientists of Korea, vol. 40, no. 4, pp. 321-330, 2014.

[24] Y.-S. Kim, J.-W. Hwang, J.-H. Jang et al., "Trapa japonica pericarp extract reduces LPS-induced inflammation in macrophages and acute lung injury in mice," Molecules, vol. 21, no. 3, p. 392, 2016.

[25] G. H. Nam, K. J. Jo, Y. S. Park et al., "Bacillus/Trapa japonica Fruit Extract Ferment Filtrate enhances human hair follicle dermal papilla cell proliferation via the Akt/ERK/GSK-3 $\beta$ signaling pathway," BMC Complementary and Alternative Medicine, vol. 19, no. 1, p. 104, 2019.

[26] G. H. Nam, K. J. Jo, Y. S. Park et al., "The peptide AC 2 isolated from Bacillus-treated Trapa japonica fruit extract rescues DHT (dihydrotestosterone)-treated human dermal papilla cells and mediates mTORC1 signaling for autophagy and apoptosis suppression," Scientific Reports, vol. 9, no. 1, p. 16903, 2019.

[27] Y.-M. Kim, H.-J. Jung, J.-S. Choi, and T.-J. Nam, "Antiwrinkle effects of a tuna heart $\mathrm{H} 2 \mathrm{O}$ fraction on $\mathrm{Hs} 27$ human fibroblasts," International Journal of Molecular Medicine, vol. 37, no. 1, pp. 92-98, 2016.

[28] M. Egeblad and Z. Werb, "New functions for the matrix metalloproteinases in cancer progression," Nature Reviews Cancer, vol. 2, no. 3, pp. 161-174, 2002.

[29] P. Pittayapruek, J. Meephansan, O. Prapapan, M. Komine, and M. Ohtsuki, "Role of matrix metalloproteinases in photoaging and photocarcinogenesis," International Journal of Molecular Sciences, vol. 17, no. 6, p. 868, 2016.

[30] L. Häkkinen, V.-J. Uitto, and H. Larjava, "Cell biology of gingival wound healing," Periodontology 2000, vol. 24, no. 1, pp. 127-152, 2000. 